LIVROS \& REDES

\title{
O polígrafo do sertão: ciências naturais e literatura na obra de Euclides da Cunha
}

\author{
Brazilian Northeast wilderness: natural sciences \\ and literature in Euclides da Cunha's works
}

\author{
Marcus Vinicius de Freitas \\ Professor adjunto de literatura brasileira e portuguesa na \\ Universidade Federal de Minas Gerais (UFMG) \\ marcusvfreitas@uol.com.br
}

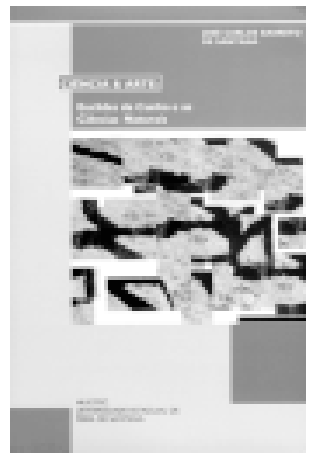

José Carlos Barreto de Santana

Ciência e arte: Euclides da Cunha e as ciências naturais São Paulo, Hucitec, 2001, 215p.
$\mathrm{M}$

onumentos textuais costumam dificultar a entrada em cena de novos olhares críticos, pois a repetição do já dito, que sobre eles recai, geralmente obstrui a visão dessas obras e impede a passagem da luz que vivifica a permanência dos textos na tradição cultural em que eles se inserem. Às vezes, somente um olhar de fora, alheio ao consagrado espaço crítico do texto, pode ser capaz de desobstruir os pontos de vista e colocar de novo em circulação a potência das obras. Este é o caso de Ciência e arte: Euclides da Cunha e as ciências naturais, de José Carlos Barreto de Santana, o qual, debruçando-se sobre a obra e o percurso intelectual de Euclides da Cunha, e em especial sobre Os sertões, enfoca o conjunto por um viés alheio àquele construído durante décadas por críticos literários, historiadores sociais, antropólogos e sociólogos.

Barreto de Santana é geólogo por formação. Seu olhar, definido pelas ciências naturais, busca iluminar o texto de Euclides a partir da presença do discurso científico, do trabalho de campo e das redes de pesquisadores das ciências naturais no percurso intelectual e nos textos do autor de Os sertões. Como historiador da ciência, Santana alinha-se a uma vertente historiográfica que privilegia a inserção da prática científica no âmbito da cultura, e se recusa a ver as ciências como um saber isolado das relações históricas e políticas. Esse duplo estatuto - de geólogo e historiador cultural das ciências naturais habilita o autor a caminhar por sendas críticas antes pouco exploradas em relação às obras de Euclides da Cunha. Assim fazendo, Santana enriquece os dois vetores que se cruzam em seu trabalho: por um lado, o autor submete à reflexão da história das ciências um texto não estritamente científico, tal como Os sertões, num procedimento heterodoxo que só amplia os horizontes da historiografia das ciências no Brasil; por outro, a crítica literária, a história e a sociologia que se debruçam sobre o cronista de Canudos dispõem, a partir de agora, de largo arsenal de novos argumentos sobre o texto, advindos da pena de um geólogo. 
Atento à própria escrita, Barreto de Santana sintetiza assim esse duplo movimento de sua proposta de trabalho:

É nessa perspectiva que pretendo analisar, numa via de mão dupla, as relações de Euclides da Cunha com as ciências naturais, dentro das especificidades contextuais de sua época, o que significa buscar entendêlos (a Euclides da Cunha e às ciências naturais) em meio a fatores diversos que incluem correntes de pensamento vigentes, as trajetórias institucionais das práticas científicas, as relações entre os personagens, compreendidos na ambiência mais geral que envolve, além das questões sociais, também os aspectos políticos, econômicos etc., que de forma geral nortearam toda uma discussão que teve como pano de fundo uma forte crença no papel fundamental das ciências, no que dizia respeito aos destinos da nação (p. 34).

Boa parte das consagradas análises sobre Os sertões buscou resolver o problema do estatuto do texto, variando entre os extremos da ficção e da ciência, com recorrência da noção de duplo estatuto, ao mesmo tempo calcado na ciência e na arte. O duplo estatuto apareceria já nas análises de contemporâneos do autor, tais como José Veríssimo e Araripe Júnior, e continuaria em nomes como Gilberto Freyre, Antonio Candido, Nicolau Sevcenko e Berthold Zilly. Na metade do século XX, Afrânio Coutinho afirmava categoricamente que Os sertões constituem uma "obra de ficção, uma narrativa heróica, uma epopéia em prosa" (apud Santana, p. 23). Luiz Costa Lima, mais recentemente, rechaça tanto o duplo estatuto quanto a apreciação ficcional, afirmando que o texto é movido por uma explicação científica que tem por borda uma ornamentação literária. Repassando esses e outros analistas de Euclides, Santana acaba por tomar marginalmente a trilha do duplo estatuto, mas com uma diferença fundamental em relação à tradição crítica: para Santana não é a definição de um estatuto duplo ou unívoco o que interessa, mas sim o reconhecimento de que o estatuto múltiplo do texto - mais do que apenas duplo - cumpriu e ainda cumpre função de marco cultural. Nessa senda, Santana segue mais de perto os passos de Valentim Facioli, que olha "Euclides da Cunha e sua obra como objeto de investigação ao qual nenhum setor ou área do conhecimento reivindica especificamente, mas dele não abre mão pelas suas possibilidades de contribuir para uma interpretação de largo espectro cultural" (p. 25).

O próprio Euclides da Cunha já avalizava o estatuto múltiplo de sua obra, ao responder, em 1902, a críticas de José Veríssimo sobre o seu largo uso de termos técnicos, dizendo que "o consórcio da ciência e da arte ... é hoje a tendência mais elevada do pensamento humano" (apud Santana, p. 22). Em 1909, no texto 'Terra sem história: impressões gerais', sobre a Amazônia, Euclides reconstrói a mesma idéia ao criticar o conjunto de viajantes que percorreram a Amazônia, de Humboldt a Goeldi, por se aterem cada um deles apenas às suas especialidades e perderem a noção do conjunto, tornando-se "geniais escrevedores de monografias" (apud Santana, p. 176). E completa ainda: "Lemo-los ... e, à medida que os distinguimos melhor, vai-se-nos turvando mais e mais o conspecto da fisionomia geral." Euclides, portanto, coloca-se, como 
bem aponta Santana, na condição de um polígrafo, que recusa a especialização e faz cruzar em sua escrita os mais diversos gêneros, com a intenção de abarcar o todo. O estatuto do texto deixa então de ser um problema para se tornar o próprio modo euclidiano de compreensão da atividade intelectual.

Após uma introdução, onde discute a história da crítica sobre a obra de Euclides da Cunha, Santana divide Ciência e arte em três capítulos, que enfocam três áreas e momentos distintos da vida do autor: o seu aprendizado científico, sua luta para se tornar lente de geologia da Escola Politécnica de São Paulo, suas relações com a comunidade científica em formação no final do século XIX, e o papel dessas relações na formação do autor e na escrita de sua obra; o papel das ciências geológicas no texto de Os sertôes e de suas fontes primárias, sejam elas a 'Caderneta de Campo', o 'Diário de uma Expedição' ou artigos de jornal publicados por Euclides. Esse capítulo dá ainda atenção à recepção do texto maior junto à comunidade geológica da época; e o percurso de Euclides na Amazônia, como encarregado da Comissão do Alto Purus.

No capítulo 1, o maior interesse está no relato crítico das frustradas tentativas euclidianas de se tornar professor da Politécnica, primeiramente na cadeira de astronomia e depois na de geologia e mineralogia. Santana revela aí um poderoso painel do complexo jogo de forças da institucionalização dos cientistas e do saber científico no final do século XIX, além de mostrar que a luta de Euclides aponta para o seu real interesse pelas ciências naturais, a ponto de Euclides considerar a carreira de professor como a saída ideal para desvencilhar-se da farda. Se o projeto não se concretizou, ao menos o conteúdo daquelas disciplinas permaneceu como cabedal que se constituiria mais tarde em elemento de força de sua obra.

No capítulo 2 está a maior contribuição do livro de Santana, que se assenta na ênfase sobre a primeira parte do texto euclidiano, 'A terra', ao contrário da maioria dos estudos anteriores, que sempre focaram sobremaneira as partes 2 e 3, 'O homem' e 'A luta', respectivamente. Santana mostra que a geologia sustenta a construção de metáforas que percorrem todo texto, constituindo um conjunto simbólico que anuncia a fatalidade do homem e o corolário da luta. Seguindo suas inclinações deterministas, Euclides da Cunha faz com que a geologia construa um pano de fundo para o embate histórico e espelhe na rocha os temas candentes da raça e da nação brasileiras.

Na análise das metáforas, Santana parte de uma série de "erros" geológicos e geográficos apontados no texto por Aroldo Azevedo, em artigo de 1950. O primeiro deles estaria no esboço geológico do Brasil, que denomina o grande planalto brasileiro como uma de suas partes, o "planalto central". Seguindo a noção de "geografia de fundação", trabalhada por Flora Süssekind, Santana mostra que Euclides precisava da palavra central para prefigurar o embate entre o poder central e os sertanejos, habitantes da terra ignota.

O segundo erro seria a denominação de "recifes" para rochedos cristalinos existentes entre Rio de Janeiro e Espírito Santo. Os primeiros estudos sobre recifes brasileiros foram feitos por Charles Frederick Hartt, entre 1865 e 1878, autor muito bem conhecido, estudado e citado por Euclides, o que 
não deixa dúvidas sobre a capacidade de Euclides de discernir sobre aquelas formações. Seu uso do termo, entretanto, se liga à tradição das navegações, que desde os primórdios da colonização consolidou a versão da existência de um "recife mítico brasileiro" a percorrer toda a costa. O caráter fundacional do uso do termo vem outra vez à tona.

A mais arrojada generalização euclidiana, criticada por Azevedo e retrabalhada por Santana, seria a da existência de um oceano cretáceoterciário cobrindo estados do Norte/Nordeste, idéia sugerida a Euclides pelas leituras de Emmanuel Liais e também de Hartt, com a ressalva de que, para Hartt, as séries cretáceas da Bahia seriam formadas pela acumulação dentro de uma bacia de água doce, hipótese também seguida por Orville Derby, discípulo de Hartt e amigo pessoal de Euclides da Cunha. A escolha euclidiana da imagem, como salienta Santana, tinha então outro objetivo, qual seja, "tinha a finalidade específica de validar, pelo ponto de vista da ciência, uma 'profecia retrospectiva', que se diferenciaria da profecia de um sertão que um dia seria praia, apenas pela seta do tempo" (p. 114). Se o Beato dizia que o sertão vai virar mar, e o mar vai virar sertão, Euclides descobre no embate geológico da terra antropomorfizada, dotada de vontade e sentimentos, a imagem da "natureza em conflito, que prefigura o embate secular entre o homem e o meio, e ainda o combate entre o litoral e o sertão, ou entre o soldado e o jagunço" (p. 113). Pelo mesmo motivo, durante a luta, a natureza surge como partícipe do combate e aliada dos sertanejos. Santana recusa, portanto, a noção simples de "erro" e mostra a intencionalidade euclidiana na construção das metáforas, com vistas ao debate histórico e político, embasado pelas ciências naturais.

O livro completa-se com uma análise do percurso de Euclides na Amazônia, em busca de construir um novo "texto vingador", que seria intitulado Paraíso perdido, projeto nunca terminado, no qual o diálogo com viajantes naturalistas e cientistas permanece como esteio do pensamento euclidiano e reforça a tese central do livro de Santana sobre a importância das ciências naturais na formação e no desenvolvimento do pensamento e do percurso intelectual de Euclides da Cunha.

Para finalizar, cabe apontar não uma falha, pois não era esse o interesse imediato do seu texto, mas uma lacuna que pode e deve ser trabalhada pelo autor: seria bom que Santana desenvolvesse mais detalhadamente o impacto das ciências naturais no âmbito da cultura letrada do final do século XIX, o que foi apenas sugerido a partir de reações de José Veríssimo, Araripe Júnior ou Ś́lvio Romero. Como se deu o embate das ciências na Academia Brasileira de Letras, a partir da presença euclidiana naquela casa? Que relações se estabeleceram, ou não, entre ciência e arte a partir das colocações de Euclides da Cunha? Qual o lugar das ciências naturais no discurso de outros "explicadores do Brasil"? O livro de José Carlos Barreto de Santana nos faz pensar sobre essas e outras questões, e assim cumpre largamente o papel a que se propôs, tornando-se, de agora em diante, bibliografia fundamental dos estudos euclidianos, em particular, e sobre a cultura do final do século XIX em geral. 